\title{
LA VIRGEN DE LOS SICARIOS DE FERNANDO VALLEJO: DISOLUCIÓN NARRATIVA DE LOS DISCURSOS DE LA VIOLENCIA EN COLOMBIA
}

\author{
POR \\ ÓsCar E. Montoya \\ University of Pennsylvania
}

\section{LA VIRGEN DE LOS SICARIOS Y LOS DISCURSOS PERIODÍSTICOS Y SOCIALES SOBRE LA VIOLENCIA}

La virgen de los sicarios (1994) de Fernando Vallejo es una de las novelas contemporáneas colombianas que, descontando la producción de Gabriel García Márquez, ha recibido mayor atención crítica. Si bien el autor tenía una extensa obra literaria previa, ${ }^{1}$ es a partir de la publicación de La virgen que gana trascendencia internacional; esto es significativo, pues esta novela constituye, en cierto modo, un desvío incidental en el ciclo narrativo de Vallejo. Podemos afirmar que el éxito de la novela fue en gran parte determinado por la coincidencia entre su tema y el interés de las agendas académicas y públicas centradas en comprender el fenómeno de la violencia en Colombia.

En La virgen de los sicarios, Fernando -el narrador, quien se define a sí mismo como gramático- cuenta su retorno a Medellín, ${ }^{2}$ de la que ha estado ausente por largos años. La ciudad está entregada a una guerra generalizada, un estado de todos contra todos, y el asesinato es el pan de cada día. En sus correrías urbanas, Fernando se enamora de

\footnotetext{
1 Vallejo había publicado previamente cinco novelas: Los días azules (1985), El fuego secreto (1987), Los caminos a Roma (1988), Años de indulgencia (1989) y Entre fantasmas (1993), todas recogidas bajo el título El río del tiempo (1999). También antes de la aparición de La virgen había publicado un ensayo (Logoi: una gramática del lenguaje literario, 1983) y una biografía sobre el poeta Porfirio Barba-Jacob (hay una primera edición de 1984 y una segunda de 1994). Tras la publicación de La virgen de los sicarios, su obra narrativa se amplió con las siguientes novelas: El desbarrancadero (2001), La rambla paralela (2002), Mi hermano el alcalde (2004) y El don de la vida (2010).

2 Medellín es la capital del departamento de Antioquia, Colombia. Fue centro industrial, principalmente en el campo de los textiles, durante la primera mitad del siglo xx. Su clase dirigente, una pujante burguesía católica, se caracterizó por ser muy emprendedora y negociante. La ciudad saltó a la fama mundial durante los años 80 y 90 por ser la sede del llamado "Cartel de Medellín", dirigido por Pablo Escobar Gaviria, que controlaba una buena parte del negocio mundial de la cocaína. La guerra del Estado contra este grupo dio lugar a una escalada de violencia que convirtió a la ciudad en una de las más violentas del mundo. La novela tiene lugar el año posterior a la muerte del capo.
} 
Alexis, un joven sicario ${ }^{3}$ con quien emprende una "limpieza social". ${ }_{4}^{4}$ Alexis asesina indiscriminadamente a cualquier persona que de una $u$ otra manera moleste $o$ indisponga a su amante. Luego de que Alexis es asesinado, el narrador conoce a Wilmar, otro sicario, con quien repite el mismo programa de exterminio. Hacia el final de la novela, Fernando descubre que Wilmar es el asesino de Alexis, pese a lo cual permanece con él hasta que el chico también es acribillado. Desilusionado de su ciudad, Fernando huye de ella.

La crítica sobre la novela se mueve en un espectro muy amplio de perspectivas. De una forma un poco simplificadora -en tanto no pretendo agotar el gran número de ensayos, artículos y análisis escritos sobre la novela- pero útil para nuestro argumento, voy a presentar las líneas dominantes de lectura, para luego plantear mi propuesta interpretativa.

Un primer acercamiento privilegia los aspectos artísticos y literarios: algunos autores -Jean Franco y Pineda Botero, por ejemplo-consideran que la misoginia y la exaltación de la violencia en la novela son resultado de la propuesta irónica de un narrador quien, a través de su aparente complacencia con los asesinatos que cometen sus amantes, nos confronta con la pérdida de valor de la vida en la sociedad colombiana. Desde la misma perspectiva, otros críticos -como L'Hoeste o Jaramillo- se centran en la relación de la novela con la tradición literaria, bien universal (L’Hoeste examina la relación con $L a$ divina comedia), o bien colombiana (Jaramillo liga a Vallejo con la práctica de la diatriba en la literatura antioqueña, observable en figuras como Fernando González, o el poeta Porfirio Barba-Jacob, tan admirado por el autor de La virgen). El aspecto lingüístico de la novela también ha llamado la atención de los académicos -como Pineda Botero, Jurado Valencia y Cardona López-, quienes resaltan la oralidad presente en la obra, el juego entre narrador y narratarios, o la transformación del lenguaje narrativo a través de la historia. Erna von der Walde resume esa perspectiva al señalar que "la fuerza del relato de Vallejo radica fundamentalmente en la operación del lenguaje" (37).

La otra línea general de lectura privilegia, sin necesariamente obviar lo literario, los contenidos políticos o sociales de la novela y sus subtextos ideológicos. Dos grandes planos de interpretación pueden identificarse aquí. Uno primero resalta el aspecto crítico o de denuncia presente en La virgen: así, Jaramillo ve en ella una búsqueda del autor

"Sicario" fue la denominación que se dio a los pistoleros, generalmente adolescentes, que trabajaban para los carteles de narcotraficantes. En Colombia se hicieron célebres tras el asesinato, el 13 de abril de 1984, del Ministro de Justicia Rodrigo Lara Bonilla - aunque su accionar venía de la década de los setenta-, no sólo en Colombia sino también en los Estados Unidos, donde actuaron durante las llamadas "guerras de la cocaína" que asolaron el estado de Florida a principios de los años ochenta. Para obtener más información sobre las guerras de la cocaína, véase el documental Cocaine Cowboys (2006), dirigido por Billy Corben. 4 "Limpieza social" fue un término usado en Colombia por los escuadrones de la muerte -grupos paramilitares-, para referirse al exterminio de sectores considerados "indeseables" en la sociedad, y que incluían desde delincuentes de baja estofa y drogadictos, hasta homosexuales y militantes de izquierda o de organizaciones de derechos humanos.

17everista Iberoamericana, Vol. LXXIX, Núms. 244-245, Julio-Diciembre 2013, 969-987 ISSN 0034-9631 (Impreso) ISSN 2154-4794 (Electrónico) de exorcizar la violencia a través de la presentación de su exceso; en una línea similar se mueven Restrepo-Gautier, Segura Bonnett, Cabañas y Castillo, quienes de diversas maneras consideran que la novela ofrece un acercamiento crítico a la historia reciente colombiana. Otro grupo de académicos plantea una visión menos halagüeña de las implicaciones ideológicas de la obra: O'Bryen señala la lectura fascista que permite la novela, aunque concluye su artículo afirmando que puede ser interpretada como “[...] a demostration of how the fascist's discourse will ultimately undermine itself through its own excess" (203). Polit-Dueñas rechaza esta matización y considera, por el contrario, que "La virgen es una novela cautivante, con chispas posmodernas, pero no deja de ser un discurso cargado de un profundo neo-fascismo" (133). El escritor Pablo Montoya, en uno de los ataques más fuertes contra la novela, considera que La virgen y en general la obra de Vallejo, debe ser leída desde la tradición de los escritores reaccionarios incapaces de afrontar el pasado y aferrados a una infancia idealizada, quienes desprecian tanto a los sectores populares como la idea de democracia.

Nuestra propuesta de lectura retoma algunos de los planteamientos que se han hecho sobre la novela, pero quiere situarlos en la pregunta acerca de las opciones literarias para narrar el estado de violencia permanente de la sociedad colombiana, en la búsqueda de estéticas y lenguajes a los que el escritor se enfrenta en medio de una proliferación de discursos sociales sobre la violencia. En este sentido debe decirse que La virgen de los sicarios es una obra que formula, de manera radical y explícita una crítica a la pretensión de los discursos del periodismo y las ciencias sociales de construir una verdad sobre los actores y los espacios de la violencia en Colombia. En ella, se ataca de manera continua a los tópicos sobre las motivaciones de los jóvenes asesinos enunciados, por ejemplo, en el tipo de ensayo -combinación de periodismo y sociología divulgativa- que proliferó en la década de los noventa en Colombia. ${ }^{5}$ Por ejemplo, sobre la relación de los sicarios con la religión -uno de los puntos donde más han insistido los violentólogos $-{ }^{6}$ Vallejo escribe:

¿Qué le pediría Alexis a la Virgen? Dicen los sociólogos que los sicarios le piden a María Auxiliadora que no les vaya a fallar, que les afine la puntería cuando disparan y que les salga bien el negocio. ¿Y cómo lo supieron? ¿Acaso son Dostoievsky o Dios

Fueron especialmente significativos los trabajos del periodista -hoy alcalde de Medellín-Alonso Salazar tales como No nacimos pa'semilla (1990), Medellin: las subculturas del narcotráfico (1992, en coautoría con la socióloga Ana María Jaramillo) y Mujeres de fuego (1993).

6 En estos textos se construye la imagen de un adolescente que habita los barrios populares de la ciudad, en hogares sin padre, donde se establece una relación edípico-religiosa con la madre; jóvenes dispuestos a hacer cualquier cosa por dinero y por brindar seguridad a sus progenitoras, y quienes asumen, fatalísticamente, que su destino es una muerte rápida, de la cual tratan de protegerse estableciendo un vínculo casi mercantil con ciertas figuras religiosas como la Virgen María.

Revista Iberoamericana, Vol. LXXIX, Núms. 244-245, Julio-Diciembre 2013, 969-987 ISSN 0034-9631 (Impreso) ISSN 2154-4794 (Electrónico) 
padre para meterse en la mente de otros? ¡No sabe uno qué está pensando, va a saber o que piensan los demás! (20)

Los cuestionamientos a los sociólogos y periodistas se extienden a lo largo de la novela. ${ }^{7}$ Vallejo repudia tanto la forma estilística de estas disciplinas como su pretensión epistemológica de poder dar cuenta de la realidad, y por eso mismo asocia estos discursos con el realismo decimonónico y su intención mimética. En dos momentos de la novela, el realismo narrativo es identificado con la labor de funcionarios judiciales: “¿Cómo llenar, en efecto, veinte pliegos de papel sellado consignando la forma en que cayó el muñeco, si nadie vio aunque todos vieran? Para eso se necesita imaginación y los funcionarios de hoy en día no la tienen, como no sea para robar y depositar en Suiza” (41). Y más adelante, cuando va a la morgue a buscar el cadáver de Wílmar, dice:

Mis ojos de hombre invisible se posaron sobre las "Observaciones" de unas de esa actas de levantamiento de cadáver, que habían dejado sobre un escritorio: "Al parecer fue por robarle los tenis -decía- pero de los hechos y de los autores nada se conoce". Y pasaba a hablar de heridas de la vena cava y paro cardiorrespiratorio tras el shock hipovolémico causado por la herida de arma cortopunzante. El lenguaje me encantó. La precisión de los términos, la convicción del estilo... Los mejores escritores de Colombia son los jueces y los secretarios de juzgado y no hay mejor novela que un sumario. (168)

Esta asociación -entre las ciencias sociales, el periodismo y un realismo literario donde priman la mímesis y la omnisciencia narrativa- refuerza su desprecio a la idea de una realidad a la cual se puede aludir por medio de un relato en que los hechos se organizan con una finalidad. Frente a estos modelos narrativos, el autor privilegia y resalta el estatuto ficcional del universo que crea. Leer La virgen como una representación realista -aunque extrema o exagerada-de la violencia en Medellín implica dejar de lado las constantes referencias a la irrealidad del mundo novelesco y su imposibilidad de ser reducido a una copia. Desde las primeras páginas de la novela, el narrador usa una imagen que resume su propuesta estética: el valor superior que asigna a la representación artística sobre la realidad. Dice refiriéndose a un recuerdo de infancia: "O sea, era como si la realidad de adentro contuviera la realidad de afuera y no viceversa, que en la carretera

Por ejemplo, sobre la transformación del lenguaje, el autor critica: "Cualquier sociólogo chambón de esos que anda por ahí analizando en las 'consejerías para la paz' concluiría de esto que al desquiciamiento de una sociedad se sigue el del idioma. iQué va! Es que el idioma es así, de por sí ya es loco" (79). "Cuando a una sociedad la empiezan a analizar los sociólogos, ay mi Dios, se jodió, como el que cae en mano del psiquiatra, por eso no analicemos y sigamos" (91). Y sobre los periodistas dice: "En la agonía de esta sociedad los periodistas son los heraldos del enterrador. Ellos y las funerarias son los únicos que se lucran. Y los médicos" (62). "Se estaban dando plomo a lo loco estos dos combos por "cuestiones territoriales' como decían antes los biólogos y como dicen ahora los sociólogos" (71). ISSN 0034-9631 (Impreso) ISSN 2154-4794 (Electrónico) a Sabaneta había una casita con un pesebre que tenía otra carretera a Sabaneta. Ir de una realidad a la otra era más alucinante que un sueño de basuco" (18). Igualmente, el narrador se asume a sí mismo como resultado de un acto de escritura: es simplemente e personaje de un libro escrito de forma desordenada y caótica, despojado de causalidad: "La trama de mi vida es la de un libro absurdo en el que lo que debería ir primero va luego. Es que ese libro mío yo no lo escribí, ya estaba escrito: simplemente lo he ido cumpliendo página por página sin decidir" (23). Y más adelante, vuelve sobre la idea de una narración desordenada, donde la línea argumental no existe o se confunde: "Pero estoy anticipando, rompiendo el orden cronológico e introduciendo el desorden" (42).

Donde más claramente se observa esa negativa a construir un relato realista es en el concepto del tiempo que domina la obra: la ciudad es una Medellín gótica vigilada por las torres de sus ciento cincuenta iglesias, donde no hay tiempo, los relojes están siempre desincronizados o detenidos, ${ }^{8}$ y los acontecimientos se repiten incesantemente. En la parte final de La virgen esto se hace mucho más claro con el episodio del Ñato: un policía que, habiendo sido asesinado treinta años atrás, vuelve a ser acribillado en la misma esquina y en las mismas circunstancias, ante lo cual el narrador, después de haber visto el cadáver, se pregunta:

Una de dos: O el que tuve ante mis ojos no era mi Ñato, o la Muerte de ociosa se había puesto a repasar sus muertos. Pero si no era el Ñato de mi juventud, ¿por qué era idéntico? ¿Y por qué lo mataron igual, y en el mismo sitio y a la misma hora? ¿No sería que la realidad en Medellín se enloqueció y se estaba repitiendo? (157)

La repetición se da también en la relación que Fernando establece con Alexis, lamado porél "el único", pero a quien reemplaza y confunde con Wílmar: "De inmediato Wílmar quiso salir al centro a estrenar. Más valiera no haber salido, no haber nacido porque de inmediato volvimos a lo de Alexis" (141).

Esta idea del tiempo circular es uno de los puntos resaltados por los críticos que establecen una relación entre esta novela y La divina comedia de Dante, la cual consideran como su referente. Esta afinidad fue resaltada inicialmente por D'Hoste, quien define $L a$ virgen como una reescritura del "Infierno": la Colombia contemporánea es similar a la Florencia medieval de Dante, acosada por luchas de fracciones; los sicarios ocupan el lugar de Virgilio como guías; el tránsito por las diversas iglesias de Medellín se asemeja

8 Así, Alexis y Fernando tienen su primer encuentro sexual en "el cuarto de las mariposas": “[...] recargado como Balzac nunca soñó, de muebles y relojes viejos; relojes y relojes viejos y requeteviejos, de muro, de mesa, por decenas, por gruesas, detenidos todos a distintas horas burlándose de la eternidad, negando el tiempo" (13). Igualmente sucede con los relojes de las torres de las iglesias: "Cuando Wílmar y yo salimos, por el pórtico de las torres, pensé que íbamos a hundirnos en un mar de bruma pero no, el dia estaba claro, recién bañado por la lluvia. 'Domus Dei Porta Coeli' leí bajo el reloj detenido en la fachada de las torres" (133).

Revista Iberoamericana, Vol. LXXIX, Núms. 244-245, Julio-Diciembre 2013, 969-987 ISSN 0034-9631 (Impreso) ISSN 2154-4794 (Electrónico) 
al viaje a través de los círculos del infierno; la mención de personajes del presente de la novela corresponde a la crítica política que hace Dante de su tiempo; se suma a esto la definición de los habitantes de Medellín como muertos vivientes y la repetición de los acontecimientos en el tiempo. Polit-Dueñas considera que, más allá de enumerar un conjunto de similitudes, es necesario desentrañar el uso de la visión apocalíptica para entender el presente de Colombia; en opinión de la autora, el uso de Dante como referencia sirve para darnos una idea de la valoración que Vallejo tiene de las letras y para entender que, para él, "[1]a literatura, entonces, es el horizonte último, y es ah donde tenemos que encontrar lo real” (126). Pero, según Polit-Dueñas, esta concepción lo sitúa de nuevo en la posición clásica del letrado latinoamericano que usa su saber literario para ubicarse en un lugar superior al mundo de los no letrados.

Desde nuestro punto de vista, el recurso a La divina comedia se interpreta en una línea análoga a la señalada por Linda Hutcheon cuando analiza el uso que la modernidad literaria hace de los recursos metanarrativos y autorreflexivos para marca una continuidad con la tradición: la referencia al poema de Dante inserta La virgen en el canon occidental, con lo cual el autor refuerza la idea de que nos encontramos en el ámbito de lo ficticio, de lo literario, donde ciertos textos, los clásicos, se convierten en una marca de jerarquía estética. Pero estas referencias no son sólo un "pago de tributo al canon". También hay una segunda lectura, más ligada a los usos de la metaficción por la narrativa denominada posmoderna: el uso de la transtextualidad, ${ }^{9}$ no para marcar continuidades sino para producir rupturas y relativizar la relación con la referencialidad histórica. Desde nuestra perspectiva, ésta segunda es la opción de Vallejo: en La virgen de los sicarios, el uso de La divina comedia sirve para construir un cronotopo ${ }^{10}$ donde los tiempos históricos y los espacios se diluyen en un mundo intemporal.

Al mismo tiempo que las menciones al saber clásico marcan el conocimiento culto del narrador, profundizan los efectos de irrealidad del mundo creado; es decir, la hipertextualidad contribuye especialmente a demoler las pretensiones de representación realista y establece como horizonte de interpretación la tradición literaria. Asimismo, s bien es cierto que -como han señalado algunos de los críticos citados-el uso del canon se puede leer como una marca de autoridad intelectual del narrador, también crea un

\footnotetext{
Genette considera que el objeto de la poética es la transtextualidad. Lo enuncia en los siguientes términos: "El objeto de la poética [...] no es el texto considerado en su singularidad [...], sino el architexto o, si se prefiere, la architextualidad del texto [...], es decir el conjunto de categorías generales o trascendentes [...] del que depende cada texto singular. Hoy yo diría, en un sentido más amplio, que este objeto es la texto en relación, manifiesta o secreta, con otros textos"' $(9-10)$

${ }_{10} \mathrm{El}$ concpto de cronotopo proviene de Mijil Baitín (Teóa y estética de la novela) y sirve para expres cexpres cosmovisión novelesca: los tipos de personajes, los eventos que se narran y el género del discurso.
}

Revista Iberoamericana, Vol. LXXIX, Núms. 244-245, Julio-Diciembre 2013, 969-98 ISSN 0034-9631 (Impreso) ISSN 2154-4794 (Electrónico) juego literario destinado a relativizar el valor de su voz narrativa, en tanto es mediada por otros textos igualmente ficticios. Esto va a ser especialmente importante en el caso de La virgen, donde la figura del narrador socava permanentemente su autoridad y su pretensión de verdad. Nada es menos creíble en la novela que las afirmaciones de una voz que de forma constante e irónica se niega a sí misma.

\section{NARRATIVAS DE UN “YO” NO TESTIGO}

Es un error considerar que el yo narrativo de La virgen corresponde a un yo autobiográfico, por más semejanzas que guarde con la figura de Fernando Vallejo autor Y no sólo por la ya clásica exigencia de la teoría literaria de distinguir autor de narrador, sino también porque este yo se distancia claramente de los patrones establecidos por la literatura de la primera persona autobiográfica y testimonial propia del "giro subjetivo contemporáneo", como tan bien lo ha denominado Leonor Arfuch. ${ }^{11}$ El yo de la novela no busca ofrecer a los lectores el relato de una vida o la ilusión de la misma, no pretende hacer su presencia verosímil o creíble. Por momentos se convierte incluso en una figura caricaturesca, tal y como sucede en el episodio en que, incólume y erguido, atraviesa una balacera descrita con las convenciones de una película de acción -seguro de que nada va a pasarle, pues, como voz dominante en la novela, no puede morir-:

Balas iban y venían, parabrisas explotaban y caían transeúntes como bolos en la barahúnda endemoniada. “¡Al suelo! ¡Al suelo!” gritaban. ¿Al suelo quién? ¿Yo? ¡Jamás! Mi dignidad me lo impide. Y seguí por entre las balas que me zumbaban en los oídos como cuchillas de afeitar. Y yo pensando en el viejo verso ¿de quién? "Oh muerte ven callada en la saeta". Pasé ileso, sano y salvo, y seguí sin mirar atrás porque la curiosidad es vicio de granujas. (32)

En otras ocasiones, el narrador se convierte en una presencia casi fantasmagórica que se desplaza por la ciudad sin restricciones corporales, capaz incluso de ir al "más allá": "No se extrañe pues usted de encontrarme en los sitios más impensados. Aquí y allá y en el más allá. Huyendo de ese ruido infernal me estoy volviendo más ubicuo que Dios en su reino" (46). Al final de la novela llega a invisibilizarse para evadir los controles

${ }^{11}$ En su trabajo El espacio biográfico. Dilemas de la subjetividad contemporánea (2002) Arfuch considera que la proliferación de las narrativas biográicas y autobiográficas en sus distintos formatos -desde el testimonio hasta el reality show- no responde sólo a una tendencia de mercado, sino a una transformación en la subjetividad contemporánea. Cuando analiza su corpus, encuentra como característica que "[...] la subjetividad que ponían en juego los relatos venía en general 'atestiguada' por la asunción del 'yo', por la insistencia en las 'vidas reales', por la autenticidad de las historias de la voz de sus protagonistas, ya sea en el directo de las cámaras o en la inscripción de la palabra gráfica, por la veracidad que el testimonio imponía al terreno resbaladizo de la ficción" (21).

Revista Iberoamericana, Vol. LXXIX, Núms. 244-245, Julio-Diciembre 2013, 969-987 ISSN 0034-9631 (Impreso) ISSN 2154-4794 (Electrónico) 
en la puerta de la morgue: "Un gentío se agolpaba afuera contra la valla de alambre de gallinero que cercaba el lote esperando entrar. Yo pasé ante los guardias de la caseta de entrada sin mirar, volviéndome a mi esencia, a lo que soy, el hombre invisible" (167)

Ese yo no puede funcionar dentro de un código realista de representación, y menos aún puede convertirse en un testigo fiable de lo que sucede, o asignar a su palabra un valor testimonial. En otras palabras, el narrador de Vallejo no es un testigo fiable ni un testimoniante de lo que sucede en Medellín, lo que nos lleva necesariamente a preguntarnos por el estatuto de ese yo que se despliega en la novela. Para hacerlo nos apoyamos en el trabajo que el filósofo italiano Giorgio Agamben ha realizado sobre el problema de la figura del testigo en las narrativas del estado de excepción y su relación con la creación literaria.

El concepto de "estado de excepción" es complejo, y no es nuestro objetivo en este artículo ocuparnos de él. Sólo resaltaremos que, según Agamben, éste consiste en la creación de un espacio donde la diferencia entre la ley y el hecho se hace indistinguible, surgiendo la posibilidad de que aún lo más terrible pueda ocurrir. Igual sucede en $L a$ virgen, en la que, como indicamos, la ausencia de ley es total; y esta ausencia hace que la realidad colombiana funcione con la lógica de espacios como el del campo de concentración, donde "Quien entraba se movía en una zona de indistinción entre exterio e interior, excepción y regla, lícito e ilícito, en que los propios conceptos de derecho subjetivo y de protección jurídica ya no tenían sentido alguno" (Homo Sacer 217). Pese a las múltiples formas que puede tomar el campo de concentración, todas tienen en común la opacidad que ofrecen a quien desee saber lo que sucede en él. La mayor parte de la información proviene de testigos, seres que bien padecieron el horror del campo o incluso lo ejercieron, pero que sólo pueden hablar desde su experiencia. Pero la condición de sobreviviente del testigo hace que su experiencia no sea la del máximo horror del campo. Quien lo ha experimentado en su totalidad es aquél que no puede contarlo porque no ha sobrevivido: la víctima que ha sido despojada de su vida y, por ende, de su lenguaje. Es decir, para Agamben, todo testimonio es un hablar por otro: "Los 'verdaderos' testigos, los testigos 'integrales' son los que no han testimoniado ni hubieran podido hacerlo. Son los que 'han tocado fondo', los musulmanes, ${ }^{12}$ los hundidos. Los que lograron salvarse, como seudotestigos, hablan en su lugar, por delegación: testimonian de un testimonio que falta" (Lo que queda de Auschwitz 34).

El problema de la representatividad de la voz que habla en el testimonio es crucial para Agamben, como lo ha sido para los estudiosos del género en América Latina. Sólo

12 Por "musulmán" se entiende al prisionero que en los campos de exterminio nazis “[...] había abandonado cualquier esperanza y que había sido abandonado por sus compañeros, no poseía ya un estado de conocimiento que le permitiera comparar entre bien y mal, nobleza y bajeza, espiritualidad y no espiritualidad. Era un cadáver ambulante, un haz de funciones físicas ya en agonía [...]" (Lo que queda de Auschwitz 41) 17eventa Reroamericana, Vol. LXXIX, Núms. 244-245, Julio-Diciembre 2013, 969-987 ISSN 0034-9631 (Impreso) ISSN 2154-4794 (Electrónico) que él no sitúa el problema dentro de las tensiones oralidad/cultura letrada, margen/ centro, posmodernidad/poscolonialidad/subalternidad que dominaron el debate en el latinoamericanismo, ${ }^{13}$ sino que lo lleva a la instancia de la constitución misma de la voz testimonial y de la construcción de la subjetividad. Apoyándose en los últimos trabajos de Benveniste, Agamben traslada la pregunta sobre el hablar por el otro -preocupación básica del testimonio y la subalternidad- al territorio de la posibilidad de hablar, ${ }^{14} \mathrm{y}$ hermana el problema del testimonio con el de la literatura: todo acto de palabra es un testimonio de la imposibilidad de hacer coincidir el viviente-la nuda vida-y el hablante:

Nohay un titular del testimonio, que hablar, testimoniar, significa entrar en un movimiento vertiginoso en el que algo se va a pique, se desubjetiva por completo y calla, y algo se subjetiva y habla sin tener -en propio- algo que decir. Un movimiento pues, en el que quien no dispone de palabras hace hablar al hablante y el que habla lleva en su misma palabra la imposibilidad de hablar, de manera que el mudo y el hablante, el no hombre y el hombre entran, en el testimonio, en una zona de indeterminación en la que es imposible asignar la posición de sujeto, identificar la "sustancia soñada" del yo y con ella, al verdadero testigo. (Lo que queda de Auschwitz 127)

El testimonio está atravesado por las mismas fuerzas contradictorias que marcan el discurso, y claro está, la literatura misma; no puede asignarse una inmunidad ética o política frente a otras formas discursivas, y tampoco puede plantearse como una

13 Para ver una de las discusiones más completas sobre el género testimonial léase Gugelberger.

${ }_{14}$ Para Agamben, cualquier acto de lenguaje es un proceso de desubjetivización. Se apoya en la separación que la lingǘstica establece entre lengua y discurso como dos realidades escindidas, entre las cuales no existe transición, sino un conjunto de signos vacíos (shifters) -entre los cuales tenemos los pronombres personales- que permiten al sujeto apropiarse de la lengua y ponerla en funcionamiento de form discursiva A csa ap

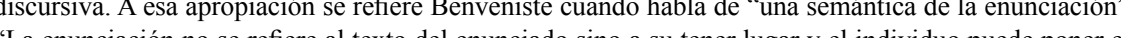
"La encicion funcion lo que, en tal decir, se dice" (122). Es decir, el habla es un paso del individuo psicosomatico al yo de la enunciación; pero, incluso en la lengua misma entendida como un sistema paradigmático de signos, el yo no puede hablar hasta que no se sitúe en la instancia del discurso. En otras palabras, el yo es siempre otro con respecto al -digámoslo así-individuo que le presta la voz; y ese yo-otro también se encuentra en una imposibilidad de hablar, en tanto se sostiene en el puro acontecimiento del lenguaje, independientemente de cualquier significado. En conclusión, para Agamben: "[...] hablar es un acto paradójico que supone al mismo tiempo, una subjetivación y una desubjetivación, y en el que el individuo viviente se apropia de la lengua en una expropiación integral, se hace hablante sólo a condición de hundirse en el silencio" (135). Esta experiencia es, en opinión del autor, la propia de la poesía: un intento de hallar un punto de articion postica, a meriencia poética, al menos la del siglo $\mathrm{xx}$, es un teritorio de exploración de esa continua desubjetivización subjetivización del yo-de la imposibilidad de hablar en el momento mismo en que se habla. Estos temas habían sido desarrollados inicialmente por Agamben ya en su obra Infancia e historia (1977), pero los desarrolló en extenso en Lo que queda de Auschwitz. El archivo y el testigo.

Revista Iberoamericana, Vol. LXXIX, Núms. 244-245, Julio-Diciembre 2013, 969-987 ISSN 0034-9631 (Impreso) ISSN 2154-4794 (Electrónico) 
instancia redentora frente a los límites de las mismas. Podemos afirmar que Agamben le devuelve al testimonio, como discurso propio de la excepcionalidad del campo, una dimensión literaria; sin que eso implique una renuncia ética -como subyace en muchas de las críticas que desde el testimonio se hacen a la literatura-, pues testimonio y literatura comparten la fractura en que surge la subjetividad humana y la experiencia misma del lenguaje. Por eso, no es gratuito que en otro de sus trabajos Agamben llame a la literatura el territorio privilegiado para los experimentos del yo ("Bartebly o de la contingencia"), en tanto allí pueden suspenderse los límites espacio temporales de la existencia humana. El signo de la literatura, para Agamben, es el de la posibilidad, no el de la representatividad.

Así pues, en el caso de La virgen, no nos interesa tanto la pregunta de si Vallejo representa de forma adecuada o justa a los jóvenes sicarios, ni de si testimonia por ellos, ni siquiera de si puede considerársele un testigo veraz de la violencia que azotaba Colombia en ese momento. Y no es nuestra preocupación porque el mismo yo dibujado en la novela niega sistemáticamente -a través de un conjunto de recursos literarios, en especial la ironía- su propia capacidad de testificar sobre cosa alguna; hasta el punto de que, si tuviéramos que definirlo, deberíamos hacerlo como el yo no-testigo. Por ejemplo, el yo narrador habla todo el tiempo sobre la situación colombiana y su proceso de degradación, pero reconoce que él no estuvo en el país durante el tiempo que éste tuvo lugar: “[...] Recuerdo que íbamos de bache en bache ipum! ipum! ipum! por esa carreterita destartalada y el carro a toda desbarajustándose, como se nos desbarajustó después Colombia, o mejor dicho como se 'les' desbarajustó a ellos porque a mí no, yo aquí no estaba, yo volví después, años y años, décadas, vuelto un viejo a morir' (9). El narrador no ha estado allí: no ha visto, no sabe. Pero aún así enuncia, porque la experiencia literaria no es resultado de la experiencia de la presencia.

El problema queda aún más claro cuando habla de las comunas de Medellín. Después de describirlas en extenso, señala que él ha subido una única vez, y que sólo las conoce indirectamente: "Las comunas son como he dicho, tremendas. Pero no me crean mucho que sólo las conozco por referencias, por las malas lenguas: casas y casas y casas, feas, feas, feas, encaramadas obscenamente las unas sobre las otras, ensordeciéndose con sus radios, día y noche, noche y día a ver cual puede más [...]" $(80) .{ }^{15}$ Lo que e narrador denomina como "malas lenguas" no es otra cosa que ese saber extendido y divulgado socialmente sobre cómo son estos espacios y sus habitantes, el cual Vallejo retoma y extrema hasta desdibujarlo grotescamente y despojarlo de cualquier pretensión de verdad. Esta deliberada deformación se evidencia en el episodio en que Vallejo retoma el tópico de "las balas rezadas"-habitual en los textos periodísticos, estudios

\footnotetext{
${ }^{15}$ Más adelante insiste en su desconocimiento de las comunas: “¿Qué cómo sé tanto de las comunas sin
} haber subido? Hombre, muy fácil, como saben los teólogos de Dios sin haberlo visto" (123).

Revista Iberoamericana, Vol. LXXIX, Núms. 244-245, Julio-Diciembre 2013, 969-987 \begin{tabular}{lll}
\hline ISSN 0034-9631 (Impreso) & ISSN 2154-4794 (Electrónico)
\end{tabular} sociológicos y representaciones artísticas de los sicarios en Colombia-, y lo presenta como una receta culinaria:

Las balas rezadas se preparan así: Pónganse seis balas en una cacerola previamente calentada hasta el rojo vivo en parrilla eléctrica. Espolvoréense luego en agua bendita obtenida de la pila de una iglesia, o suministrada, garantizada, por la parroquia de San Judas Tadeo, barrio de Castilla, comuna noroccidental [...] y mientras tanto va rezando el que las reza con la fe del carbonero: "Por la gracia de San Judas Tadeo (o el Seño Caído de Girardota o el padre Arcila o el santo de tu devoción) que estas balas de esta suerte consagradas den en el blanco si fallar, y que no sufra el difunto. Amén". ¿Que por qué digo que con la fe del carbonero? Ah yo no sé, de estas cosas no entiendo, nunca he rezado una bala. Ni nadie, nadie, nadie me ha visto hasta ahora disparar. (90)

Otro punto donde se observa el funcionamiento de esta operación irónica es cuando el narrador hace de guía y traductor para extranjeros sedientos del espectáculo de la violencia colombiana. ${ }^{16} \mathrm{El}$ yo narrador oficia de cicerone en territorios que él tampoco conoce: nos traduce un lenguaje que no es el suyo, cuenta la historia de un país del que ha estado ausente y que no reconoce como propio. Es el etnólogo que no viaja pero que habla de oídas, el sociólogo que construye su teoría sobre lo evidente, el historiador del lugar común, el reportero o narrador sensacionalista que da a su público lo que le pide. En consecuencia, más que usar el saber como un ejercicio letrado de dominio, el narrador de Vallejo está distanciándose y burlándose de los diversos saberes y narrativas que se han ocupado de la realidad colombiana contemporánea.

El yo que aparece en la novela es, ante todo, un espacio de travestismos, de transformaciones: en algún momento se declara muerto, ${ }^{17}$ en otro se despoja de su nombre: "De suerte que aunque siga siendo yo yo ya no tenga nombre" (95); en un pasaje viste una túnica sagrada ante las que se desintegran las balas; en otras secuencias, como ya mencionamos, atraviesa incólume entre disparos o se hace invisible. En conclusión, podemos afirmar que el yo narrativo de Vallejo no busca imponer una verdad autobiográfica o testimonial: no puede atestiguar de nada distinto a los juegos mismos del yo, los cuales se desplazan libremente entre lo real y lo ficticio; y, ante todo, gusta apropiarse de los lenguajes sociales para construir su relato, su voz, contra ellos.

${ }^{16}$ Esto nos remite, además, al alto de nivel de conciencia que tiene Vallejo de los circuitos de circulación de su obra, de la fascinación pública con las ficciones de la violencia, incluso de las agendas académicas que privilegian su análisis.

17 "En la jerga de las comunas o argot comunero que está formado en esencia de un viejo fondo de idioma local de Antioquia, que fue el que hablé yo cuando vivo [...]” (31, énfasis mío).

Revista Iberoamericana, Vol. LXXIX, Núms. 244-245, Julio-Diciembre 2013, 969-987 ISSN 0034-9631 (Impreso) ISSN 2154-4794 (Electrónico) 


\section{LAS NARRATIVAS DEL SUBLIME CRIMINAL}

Hay otro universo discursivo con el cual la obra establece una relación más ambigua y que subyace en los cuestionamientos éticos o políticos que diversos autores han hecho a La virgen de los sicarios. Nos referimos al "discurso de lo inenarrable" o al "sublime criminal", que ha sido una de las estrategias del romanticismo, e incluso de las vanguardias para aproximarse estéticamente al fenómeno del crimen. ${ }^{18}$ De forma sencilla y resumida, esta corriente plantea que el crimen es una experiencia extrema, última, que comparte rasgos con la vivencia mística o sacrificial. En cierto sentido, busca asignarle un aura trascendente o religiosa a la violencia que azota el mundo contemporáneo.

En su análisis sobre los campos de concentración nazis, Giorgio Agamben cuestiona las corrientes de pensamiento que asignan un significado trascendente o místico a la violencia colectiva. Así, por ejemplo, se distancia de quienes, para hablar del exterminio judío, usan el término holocausto, porque establecen “[...] una conexión, aunque sea lejana, entre Auschwitz y el olah bíblico, y entre la muerte en las cámaras de gas y la 'entrega total a motivos sagrados y superiores' [, lo cual] no puede dejar de sonar como una burla" (Lo que queda de Auschwitz 31). Igualmente se niega a postular una indecibilidad del mismo, pues esto implica "[...] conferir al exterminio el prestigio de la mística [...]"(31). Para Agamben, el terreno donde se desarrollan los crímenes colectivos contemporáneos es el de la biopolítica, no el de la sacralidad; y todos los intentos de

${ }^{18}$ El concepto de lo sublime goza de una amplia tradición en el pensamiento estético y filosófico occidental; y en décadas recientes, el postestructuralismo lo ha recuperado como una herramientaclave

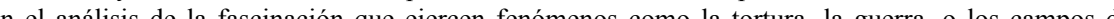
exterminio Desdest externio. Desde sus origes ability to apprehend, to know, and to express a thought or sensation is defeated. Yet through this very defeat, the mind gets a feeling for that which lies beyond thought and language $[\ldots]$ the concept of the sublime lends itself well to the idea of the transcendent, whether encountered in the Hebrew Bible or in the poetics of Romanticism" (Shaw 3). Fueron los románticos quienes trascendieron el concepto clásico de lo sublime -desarrollado fundamentalmente por Kant-, y quienes lo trasladaron del campo de la expresión de fenómenos como el crimen o la violencia. Esto se observa con claridad en la obra de Thomas De Quincey, quien explora la dimensión estética de actos como el asesinato, capaces de sacar al individuo de su existencia normal y de desbordarlo en una experiencia que va más allá de los límite del lenguaje y la representación. Para Joel Black, el texto "On Murder” de Quincey “[ . . constitutes

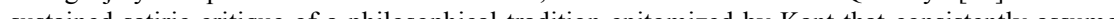
a sustained satic critche of a philosophical traditen coherent, nomprom Qetween the experientia fort orm, De Quincey demonstrated the aesthetic subversion of the beautiful by the sublime, and more generally, the philosophical subversion of ethics by aesthetics" (15)

La belleza que puede emanar del asesinato o del ejercicio de la violencia también hace surgir una figura típica del romanticismo: el criminal artista, dotado de una belleza especial, y que realiza sus accione en busca de trascendencia. El vínculo entre lo sublime y lo trascendente ha sido puesto en entredicho de manera sistemática por el pensamiento posmodernista, que lo asocia fundamentalmente con el vacío de significación inherente a toda búsqueda de representación (Shaw).

174 Revista Iberoamericana, Vol. LXXIX, Núms. 244-245, Julio-Diciembre 2013, 969-987 ISSN 0034-9631 (Impreso) ISSN 2154-4794 (Electrónico) llevarla al plano de lo sagrado quedan expuestas a terminar celebrando de una u otra forma la muerte $-\mathrm{y}$, por ese camino, justificando el fascismo-.${ }^{19}$ La dimensión en que desde su enfoque teórico, debe ser comprendido el asesinato masivo -en su caso, el de los judíos bajo el III Reich nazi- no comprende elementos religiosos:

El judío bajo el nazismo es el referente negativo privilegiado de la nueva soberanía política y, como tal, un caso flagrante de homo sacer, en el sentido de una vida a la que se puede dar muerte pero que es insacrificable. ${ }^{20}$ El matarlos no constituye, por eso, como veremos, la ejecución de una pena capital ni un sacrificio, sino tan sólo la actualización de una simple posibilidad de recibir la muerte que es inherente a la condición de judío como tal. La verdad dificil de aceptar [incluso] para las propias víctimas, pero que con todo, debemos tener el valor de no cubrir con velos sacrificiales, es que los judios no fueron exterminados en el transcurso de un delirante y gigantesco holocausto, sino, literalmente, tal como Hitler lo habia anunciado, "como piojos", es decir como nuda vida. (Homo sacer 147, énfasis mío)

En la novela de Vallejo, hay una tensión constante en la enunciación de los asesinatos que la pueblan. En algunos casos están desprovistos de significado; pero también el narrador recurre con frecuencia a elementos propios de la sacralidad para describir, si no el crimen mismo, el efecto que éste produce en sus amantes asesinos. Fernando parece estar en búsqueda de una experiencia trascendente-incomunicable, en palabras de Agamben-, como puede verse en algunas descripciones; por ejemplo, en el primer asesinato que Alexis comete en su presencia:

Corrió hacia el hippie, se le adelantó, dio media vuelta, sacó el revólver y a pocos palmos le chantó un tiro en la frente, en el puro centro, donde el miércoles de ceniza te ponen la santa cruz. ¡Tas! Un solo tiro, seco, ineluctable, rotundo, que mandó a la gonorrea esa

\footnotetext{
19 En este sentido, es muy valioso el análisis que Agamben hace del pensamiento de Bataille, uno de los grandes teóricos contemporáneos del sacrificio: "De este modo, Bataille confunde desde el prime momento el cuerpo político del hombre sagrado, expuesto absolutamente a que se le mate pero que es también absolutamente insacrificable, que se inscribe en la lógica de la excepción, con el prestigio del cuerpo sacrificial, definido de manera diversa por la lógica de la transgresión. Si corresponde a Bataille el mérito de haber la soberanía, la vida queda en él completam a de sagrado. Por ese camino no era posible otra cosa que la repetición, real o en forma de farsa, del bando soberano, y se comprende bien que Benjamin llegara a estigmatizar (según el testimonio de Klossowski) las investigaciones de grupo de Acéphale con una forma perentoria: Vous travaillez pour le fascisme" (Homo Sacer 145).

20 La definición de homo sacer, tal como Giorgio Agamben la desarrolla en su trabajo Homo Sacer. El poder soberano y la nuda vida (1995), se refiere a una oscura figura del derecho romano que permite da muerte a ciertos individuos sin cometer asesinato o realizar sacrificio; es decir, poniéndolos por fuera de los ámbitos del derecho o la religión y situándolos es una esfera exterior a la comunidad. Esta figura ha sido central en el desarrollo de su teoría biopolitica.
}

27. Revista Iberoamericana, Vol. LXXIX, Núms. 244-245, Julio-Diciembre 2013, 969-987 ISSN 0034-9631 (Impreso) ISSN 2154-4794 (Electrónico) 
con su ruido a la profundidad de los infiernos. ¡Cuántas veces no he pasado la escena por mi cabeza en ralenti! Veo sus ojos verdes viéndolo. Verdes turbios. Embriagado en lo irrepetible del instante. ¡Tas! Un solo tiro, sin comentarios. (36-37, énfasis mío)

Un trance similar se produce cuando Alexis asesina a tres soldados: "Era tan asombroso el suceso, tan imprevisto el suceso que no sabía qué hacer. Alexis tampoco. Se quedó viendo los cadáveres como hipnotizado, mirándoles los ojos" (53, énfasis mío). El narrador debe retraer al joven al orden de la experiencia cotidiana, sacarlo del trance en que el crimen lo ha sumido. Lo que fascina a Fernando son los ojos del asesino mirando a sus víctimas: esa embriaguez a la que él no accede, el oscuro placer que contempla en ellos, pero que le es ajeno. Los sicarios le permiten, aunque sea en calidad de testigo acompañante, acercarse a esa supuesta experiencia sublime, sagrada que no encuentra lugar en ninguna otra de sus vivencias dentro de la ciudad masificada y vulgar a la que ha vuelto.

En la novela, además, se realiza una doble negación de lo humano. Por un lado, se reduce a los habitantes de Medellín a su más clara condición de homo sacer: vida que puede ser matada sin que se cometa homicidio o sacrificio; por el otro, eleva a los sicarios a una dimensión suprahumana, al nombrarlos con un lenguaje sacro, dotándolos de los atributos de belleza perturbadora que el romanticismo asignó al "sublime criminal" -tal como señala Mario Praz en su clásico The Romantic Agony. ${ }^{21}$ Los sicarios que Fernando convierte en objeto de su deseo son bellos, y su relación con la muerte los sitúa para él en un ámbito fuera de lo cotidiano; los eleva a criaturas sagradas, ángeles: "Sin alias, sin apellido, con su solo nombre, Alexis era el Ángel Exterminador que había descendido sobre Medellín a acabar con su raza perversa" (78). "El eco del eco del eco... Muchísimo antes de que el eco se extinguiera el guardián de la tumba se desplomó. Luego el eco murió en sus armónicos. El Ángel Exterminador se había convertido en el Ángel de Silencio" (102). ${ }^{22}$

Pero este discurso también fracasa -al igual que los provenientes de las ciencias sociales o del periodismo- en su afán de convertirse en el lenguaje capaz de nombrar el horror en la sociedad colombiana. La búsqueda de un significado trascendente en la vida de los “ángeles asesinos" sólo conduce al vacío. Se produce así una coincidencia con la

\footnotetext{
${ }^{2}$ En el capítulo "The Metamorphoses of Satan", Praz muestra cómo, a su vez, este criminal viene de la imagen que Milton construye de Satanás en Paradise Lost: una belleza caída, un ser rodeado de 1 grandeza del dolor y la muerte. El mal es dotado, en esta tradición, de una belleza sobrenatural: "Accursed beauty is a permanent attribute of Satan" (56).

22 La asociación entre el sicario y los ángeles nos sirve también para dotar de otro sentido al uso que Vallejo hace de La divina comedia como hipotexto de su novela; pues, como señala Auerbach, "[...] the marriage of the human and the divine, the humble and the sublime, reaches its apogee in the Divine Comedy by Dante Alighieri”' (Shaw 21). Este matrimonio entre lo divino y lo humano se realiza en Vallejo a través de
} la figura del sicario. I7t Revista Iberoamericana, Vol. LXXIX, Núms. 244-245, Julio-Diciembre 2013, 969-987 ISSN 0034-9631 (Impreso) ISSN 2154-4794 (Electrónico) lectura que el posestructuralismo ha hecho del concepto de lo sublime, al considerar que éste " $[. .$.$] ought not be to conceived as a transcendent 'Thing-in-itself' beyond the field$ of representation, but rather as an indicator of the traumatic emptiness, the primordial lack, residing at the heart of all forms of symbolization" (Shaw 138).

Esta de-sublimación de los sicarios se produce en tres momentos específicos de la novela, y los tres están ligados al contacto del narrador con manifestaciones de la nuda vida. El primero de ellos es el encuentro de Fernando y Alexis con un perro malherido en una quebrada de la ciudad. Alexis, que nunca ha expresado la menor duda o remordimiento para asesinar a seres humanos, se declara incapaz de matar al animal, y es el propio Fernando quien debe hacerlo para que el perro no siga sufriendo. Este episodio es uno de los más misteriosos de la novela. Puede ser interpretado en dos líneas. Una, la de la sacralidad: el animal es aquél que está libre de pecado, y por lo tanto es inocente; su muerte, a diferencia de la de los humanos, sí constituye un crimen. Dos, en la figura del animal se revela la humanidad del hombre, y por eso, al matarlo se descubre la dimensión real del asesinato. Es en esta segunda línea analítica que queremos encauzarnos. Para ello, nos valemos de las reflexiones sobre lo anima trazadas también por Giorgio Agamben, quien sitúa este problema como uno de los principales de su teoría biopolítica:

[...] si la cesura entre lo humano y lo animal pasa sobre todo por el interior del hombre, entonces la cuestión del hombre -y del "humanismo"- debe ser formulada en nuevos términos. En nuestra cultura, el hombre ha sido siempre pensado como la articulación de un cuerpo y de un alma, de un viviente y de un lógos, de un elemento natural (o animal) y de un elemento sobrenatural, social o divino. Tenemos que aprender, en cambio, a pensar en el hombre como lo que resulta de la desconexión de esos dos elementos y no investigar el misterio metafísico de la conjunción, sino el misterio práctico y político de la separación. ¿Qué es el hombre, si siempre es el lugar -y, al mismo tiempo, el resultado- de divisiones y cesuras incesantes? Trabajar sobre estas divisiones, preguntarse en qué modo [...] el hombre ha sido separado del no-hombre y el animal de lo humano es más urgente que tomar posición acerca de las grandes cuestiones, acerca de los denominados valores y derechos humanos. (Lo abierto 35)

El encuentro con lo animal es el límite que la novela no puede cruzar. Alexis deja de ser una criatura extraterrena, un ángel, y se muestra como lo que es: un adolescente compungido ante el dolor de otra criatura.

Algo similar sucede en el segundo momento. Alexis ha sido asesinado, y el narrador sube a la comuna a buscar a la madre del chico. Cuando la encuentra, se sorprende de las míseras condiciones en que vive, y dice: "Ni en esta pobre mujer ni en ninguno de sus niños reconocí un solo rasgo de Alexis, nada pero nada de su esplendor. Los milagros son así, burleteros" (124). Asimismo declara sentir "[...] una inmensa compasión por ella, por sus niños, por los perros abandonados [...]" (124). A lo largo de la novela, el

Revista Iberoamericana, Vol. LXXIX, Núms. 244-245, Julio-Diciembre 2013, 969-987 ISSN 0034-9631 (Impreso) $\quad$ ISSN 2154-4794 (Electrónico) 
narrador ha expresado su especial odio por las mujeres y los niños, fundamentalmente porque son la expresión de un ciclo vital contra el cual se rebela. ${ }^{23}$ Pero ahora los pone en el mismo plano de los animales, las únicas criaturas que, según él, son dignas de vivir. La identificación entre lo animal y lo humano produce en este fragmento de la novela un efecto contrario al que impulsa la acción criminal de los sicarios: si antes cualquiera podía ser asesinado por ser nuda vida -principio con el que actúa Alexis-, ahora nadie merece ser asesinado precisamente por su condición animal, es decir, por su nuda vida.

Es cierto que tras este fragmento Fernando se encuentra con Wílmar y recomienza su programa de exterminio. Pero también lo es que el libro cambia de tono a partir de las dos secuencias señaladas: el ciclo de las repeticiones se intensifica, y la novela parece parodiarse a sí misma. Wílmar es una repetición de Alexis, pero es también una especie de sombra del mismo; los muertos vuelven en una espectrografía o fantasmagoría, que transforma a la ciudad en un territorio cenagoso donde todo lo que acontece tiene e peso de lo ya sucedido. En cierto modo, si el texto se abre con la búsqueda sublime de un amor criminal en la mejor tradición del romanticismo, se cierra como una película de zombis: la novela de Vallejo bien podría resumirse como el camino que va de la reescritura contemporánea de La Divina comedia al triunfo de El regreso de los muertos vivientes.

El final de la novela es el tercer momento de quiebra del discurso del "sublime criminal": el reconocimiento de su propia imposibilidad para nombrar el infierno urbano - una metáfora más del campo de concentración- en que se ha transformado Medellín. Fernando, convertido en una criatura invisible, cuenta -por primera vez en tercera persona- su viaje a la morgue en busca del cadáver de Wílmar. Así describe su paseo entre los cadáveres que pueblan las mesas forenses:

Era una sala alta, espaciosa, la de necropsias, con unas treinta mesas de disección ocupadas todas por los del último turno. Todas, todas, todas y todos hombres y casi todo eran jóvenes. Es decir, fueron. Ahora eran cadáveres, materia inerte. Desnudos, rajados en canal como reses, les habían extraído las vísceras para analizarlas y no les habían dejado nada de sustancia qué comer a los gusanos. El hombre invisible se enteró de que todos esos corazones, hígados, riñones, pulmones, tripas irían a una fosa común. (169)

\footnotetext{
${ }^{23}$ Por ejemplo, en un episodio Fernando expresa el profundo disgusto que le causan una mujer y sus dos hijos pequeños, y su satisfacción cuando Wílmar los asesina: bamos en uno de esos buses atestados en el calor infernal del mediodía y oyendo vallenatos a todo taco. Y como si ficran poco el calor y el radio, una señora con dos niños en pleno libetinaje. uno, de teta, en su más enfurecido berrinche, cagado sensu stricto de la ira. $Y$ el hermanito brincando, manotiando, jodiendo. ¿Y la mamá? Ella en la luna, como si nada, poniendo cara de Mona Lisa la delincuente, la desgraciada, convencida de que la maternidad es sagrada [...] Y con la taza llena hasta el tope, rebosada hasta el rebose, he aquí que en Wílmar encarna el Rey Herodes. Y que saca el Santo Rey el tote y truena tres veces. ¡Tas! ¡Tas! ¡Tas! Una para la mamá, y dos para sus dos redrojos. Una pepita para la mamá en su corazón de madre, y dos para sus angelitos en sus corazoncitos tiernos. Si hace dos mil años se le escapó a Egipto el impostor éstos no, ya el Santo Rey estaba curado de engaños (144-145).
}

17. Revista Iberoamericana, Vol. LXXIX, Núms. 244-245, Julio-Diciembre 2013, 969-987 ISSN 0034-9631 (Impreso) ISSN 2154-4794 (Electrónico)
En esta descripción no sólo no hay espacio para pensar en la dignidad de la muerte, sino que también se revela el agotamiento de todos los lenguajes para nombrar esa acumulación de cuerpos inertes, materia orgánica, resultante del horror contemporáneo. Ni las ciencias sociales, ni el periodismo, ni el realismo, ni las tradiciones románticas o vanguardistas poseen las claves para narrar la realidad que Fernando contempla. Así lo dice en las últimas páginas, al mirar las combinaciones de los cuerpos sobre las mesas: "El hombre invisible recordó esas combinaciones de objetos mágicas, insólitas con que soñaban los surrealistas, como por ejemplo un paraguas sobre una mesa de disección. ¡Surrealistas estúpidos! Pasaron por este mundo castos y puros sin entender nada de nada, ni de la vida ni del surrealismo. El pobre surrealismo se estrella en añicos contra la realidad de Colombia" (170)

El discurso del narrador frente a la muerte cambia dramáticamente al final de la novela: su retórica del odio se apaga. Si a lo largo de la obra declara que todos los habitantes de la ciudad son culpables, y por tanto merecedores de la muerte que Alexis y Wílmar prodigan, La virgen de los sicarios se cierra con una declaración de inocencia universal: "Pobres seres inocentes, sacados sin motivo de la nada y lanzados en el vértigo del tiempo" (174).

CONCLUSIÓN

La Medellín de Vallejo es construida como un territorio apestado, una ciudad donde sus habitantes son descritos como zombis: seres sin derechos, sometidos a poderes arbitrarios, vida que cualquiera puede tomar y destruir; constituye una especie de reelaboración contemporánea del infierno dantesco, donde se ha perdido toda esperanza. No es gratuito que en la novela la solución del narrador sea, por un lado, poner en entredicho todas las formas discursivas usadas para intentar nombrar la violencia, desde el realismo periodístico hasta la sublimación romántica; y, por el otro, reconocer que su propio lenguaje ya sólo puede dar testimonio de la imposibilidad de testimoniar e horror del presente. En esta tensión puede leerse una negociación entre sus búsquedas estéticas y las exigencias formuladas por un mercado ávido de escuchar relatos sobre la realidad de esos países distópicos: tierras pobladas por muertos vivientes y asesinos angelicales, donde el relato de la ley se ha derrumbado y todos sus habitantes han pasado a la condición de vida desnuda.
Revista Iberoamericana, Vol. LXXIX, Núms. 244-245, Julio-Diciembre 2013, 969-987 ISSN 0034-9631 (Impreso) 


\section{OBRAS CITADAS}

Agamben, Giorgio. Homo Sacer. El poder soberano y la nuda vida. Valencia: Pretextos, 1998.

"Bartebly o de la contingencia". Preferiría no hacerlo. Bartebly el escribiente, de Herman Melville seguido de tres ensayos sobre Bartebly de Gilles Deleuze, Giorgio Agamben, José Luis Pardo. Valencia: Pre-textos, 2000.

Lo que queda de Auschwitz. Homo sacer III. El archivo y el testigo. Valencia: Pre-textos, 2000.

Lo abierto. El hombre y el animal. Buenos Aires: Adriana Hidalgo, 2007.

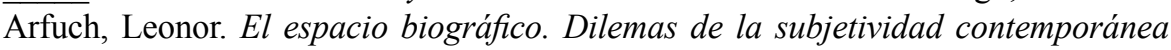
Buenos Aires: FCE, 2002.

Batjin, Mijail. Teoría y estética de la novela. Trabajos de investigación. Madrid: Taurus, 1989.

Black, Joel. The Aesthetics of Murder: A Study in Romantic Literature and Contemporary Culture. Baltimore: Johns Hopkins UP, 1991.

Cabañas, Miguel. "El sicario en su alegoría: la ficcionalización de la violencia en la novela colombiana del siglo xx". Taller de Letras 31(2002): 7-20.

Cardona López, José. "Literatura y narcotráfico: Laura Restrepo, Fernando Vallejo, Darío Jaramillo Agudelo". Literatura y cultura. Narrativa colombiana del siglo XX. Vol. 2. María Mercedes Jaramillo, Betty Osorio, Angela I. Robledo, eds. Bogotá: Ministerio de Cultura, 2000. 378-406.

Castillo, Carolina. "Colombia: violencia y narración”. Espéculo: Revista de Estudios Literarios 27 (2004) <http:www.ucm.es/info/especulo/numero27/index.html>.

Corben, Billy. Cocaine Cowboys. Rakontur, 2006.

Fernández L'Hoeste, Héctor. "La virgen de los sicarios o las visiones dantescas de Fernando Vallejo". Hispania 83/4 (2000): 757-767.

Franco, Jean. Decadencia y caída de la ciudad letrada. La literatura latinoamericana durante la guerra fría. Madrid: Debate, 2003.

Genette, Gérard. Palimpsestos. La literatura en segundo grado. Madrid: Tauros, 1989.

Gugelberger, Georg M. The Real Thing. Testimonial Discourse and Latin America. Durham: Duke UP, 1996.

Hutcheon, Linda. A Poetics of Postmodernism: History, Theory, Fiction. Nueva York: Routledge, 1988.

Jaramillo, María Mercedes. "Fernando Vallejo: desacralización y memoria”. Literatura y cultura. Narrativa colombiana del siglo XX. Vol. 2. Betty Osorio, Ángela I. Robledo, eds. Bogotá: Ministerio de Cultura, 2000. 407-439.

Jurado Valencia, Fabio. "La soberbia del lenguaje en la narrativa de Fernando Vallejo". La novela colombiana ante la crítica 1975-1990. Luz Mary Giraldo, ed. Bogotá: Centro Editorial Javeriano, 1994. 341-356.

1727 Revista Iberoamericana, Vol. LXXIX, Núms. 244-245, Julio-Diciembre 2013, 969-987 ISSN 0034-9631 (Impreso) 1SSN 2154-4794 (Electrónico)
Montoya, Pablo. "Fernando Vallejo: demoliciones de un reaccionario". Número 54 (2007): 18-28.

O'Bryen, Rory. "Representations of the City in the Narrative of Fernando Vallejo." Journal of Latin American Cultural Studies 13/2 (2004): 195-204.

Pineda Botero, Álvaro. Estudios críticos sobre la novela colombiana 1990-2004. Medellín: Fondo Editorial Universidad EAFIT, 2005.

Polit-Dueñas, Gabriela “'Sicarios, delirantes y los efectos del narcotráfico en la literatura", Hispanic Review 74/2 (2006): 119-142.

Praz, Mario. The Romantic Agony. Londres: Oxford UP, 1951.

Restrepo-Gautier, Pablo. "Lo sublime y el caos urbano: visiones apocalípticas de Medellín en La virgen de los sicarios de Fernando Vallejo". Chasqui: Revista de Literatura Latinoamericana 33/1 (2004): 96-105.

Salazar, Alonso y Ana María Jaramillo. Medellín: las subculturas del narcotráfico. Bogotá: Cinep, 1992.

Salazar, Alonso. Mujeres de fuego. Medellín: Corporación Región, 1993. No nacimos pa semilla. Bogotá: Cinep, Corporación Región, 1990.

Segura Bonnett, Camila. "Kinismo y melodrama en La virgen de los sicarios y Rosario Tijeras". Estudios de Literatura Colombiana 14 (2004): 111-136.

Shaw, Philip. The Sublime. Londres: Routledge, 2006.

Vallejo, Fernando. La virgen de los sicarios. Madrid: Punto de Lectura, 2006.

Walde Uribe, Erna von der. "La novela de sicarios y la violencia en Colombia". Iberoamericana 1/3 (2001): 27-40.
Revista Iberoamericana, Vol. LXXIX, Núms. 244-245, Julio-Diciembre 2013, 969-987 ISSN 0034-9631 (Impreso) 
